\title{
ÉTICA Y CALIDAD EN SALUD. FILOTECNIA VERSUS FILANTROPÍA
}

\author{
José Geraldo de Freitas Drumond*
}

\begin{abstract}
Resumen: La profesión médica tiene el carácter ético de la práctica de la virtud de la excelencia. Desde Hipócrates hay dos tipos de éticas: la filotecnia y la filantropía. La primera se refiere a la ética de la técnica y la última a la humanista. Hoy, la excelencia resulta del entrenamiento y la formación intelectual realizados en el proceso educativo formal. La excelencia, otro nombre para calidad en salud, tiene la finalidad de atender a una demanda social trayendo satisfacción para quienes se sirven de ella. Las tecnologías modernas sólo se justifican cuando proporcionan una efectiva mejoría de la calidad de vida y salud para el ser humano; de lo contrario, son una forma de dominación y usurpación de la cultura médica por la máquina o, incluso, la sumisión del paciente a la ideología del cientificismo o la lógica de mercado, contribuyendo a la obtención de lucros injustificables por la industria de la salud, al no evaluar la prudente relación entre el coste, los riesgos y los posibles beneficios obtenidos por el paciente.
\end{abstract}

Palabras clave: ética, calidad en salud, tecnología y excelencia en salud

\section{ETHICS AND HEALTH CARE QUALITY. PHILOTECNIA VERSUS PHILANTHROPY}

Abstract: The medical profession has the ethical practice of the virtue of excellence. There have been since Hippocrates two ethics: the "philotechny" and the philanthropy. The first refers to the ethics of the technique and the latter, to the humanistic ethics. Nowadays, excellence results from training ande intellectual fromation acquired along formal education whose purpose is to assist a social demand, bringin satisfaction to anyone im need of it. Modern technologies are justified only if they are conditioned to an effective improvement of life quality and health of human beings and don't represent a form of domination and usurpation of medical culture through machines, or even patient's submission to the ideology of scientic logic of the market, which contributes to the unjustified profits for the health industry and its disregard concerning prudent assessment of the relationship between costs, risks and potential benefits to be received by the patient.

Key words: ethics, excellence, technology and health quality

\section{ÉTICA E QUALIDADE EM SAÚDE: FILOTECNIA VERSUS FILANTROPIA}

Resumo: A profissão médica tem como caráter ético a prática da virtude da excelência. Desde Hipócrates existem duas éticas: a filotecnia e a filantropia. A primeira se refere à ética da técnica e a segunda, à ética humanista. Hodiernamente, a excelência resulta do treinamento e da formação intelectual adquiridos durante o processo educacional formal e cuja finalidade é atender a uma demanda social, sendo úteis e trazendo satisfação para quem dela se serve. As tecnologias modernas só se justificam se estiverem condicionadas a uma efetiva melhoria da qualidade de vida e de saúde do ser humano; senão, representam uma forma de dominação e usurpação da cultura médica pela máquina ou, ainda, a submissão do paciente à ideologia do cientificismo ou à lógica de mercado, que contribuem para a obtenção de lucros injustificáveis pela indústria da saúde e negligenciam a avaliação prudente da relação entre o custo, os riscos e os possíveis benefícios a serem auferidos pelo paciente.

Palavras chave: ética, qualidade em saúde, tecnologia e excelência em salud

* Profesor Titular de Bioética y Ética Médica de la Universidad Estatal de Montes Claros, Minas Gerais, Brasil.

Correspondencia: jdrugon@uol.com.br 


\section{Antecedentes históricos}

Desde la aparición del hombre en el planeta, la medicina se caracterizó como un acto de socorro al ser humano. Sus primeros practicantes -hechiceros o chamanes- utilizaban rezos, exorcismos e invocaciones a las divinidades, tratamientos físicos (frío, calor), plantas medicinales y hasta intervervenciones cruentas (trepanaciones) como forma de liberar el enfermo de los demonios.

"Médico" es un vocablo derivado de la palabra sánscrita meth, que significa maldecir, conjurar; y medicus, palabra latina sinónimo de mediador, hechicero. En su cuna, la medicina se integró a la paidea griega y sus primeros artífices, además de ostentar prestigio intelectual y social, eran considerados representantes de la más refinada ética profesional.

En los textos del Corpus Hippocraticum, la colección de la escuela de Cos, había dos modalidades de moral: la ética y la etiqueta. La "ética de la filantropía" (del griego philos: amigo, y anthropós: hombre, humanidad) se caracterizaba por una moral altruista, de amor a la humanidad, centrada en el beneficio del enfermo, que exige la práctica de virtudes humanitarias, como por ejemplo la compasión, el respeto y la honestidad.

Ya la "ética de la filotecnia" estaba explicitada por una moral egoísta, preocupada con los intereses profesionales y cuyo objetivo era la preservación de la reputación del médico a través de la construcción de una imagen decente o de buena apariencia, del carácter y de la conducta profesional(1).

El "ethos" hipocrático evolucionó desde la época clásica hasta el helenismo, pasando por dos fases características. La primera, la fase de la ética hipocrática primitiva, situada en el siglo $\mathrm{V}$ a.C., se mostraba completamente ajena a los ideales del humanismo médico tradicional, es decir, no era una ética de la atención o del cuidado del paciente, sino de resultados o éxitos técnicos. El arte (tekhné) era el que conducía al cuidado del hombre ("amor al hombre por amor al arte"). Por esa época, las reglas de conducta del médico se ajustaban a la moral de la eficacia profesional, proporcionándole tanto prestigio que, a semejanza de los demás artesanos griegos, el médico era juzgado en razón de su peritaje o calidad(2).

La segunda fase ocurrió durante el período comprendido entre los siglos III y II a.C., con la transformación de la práctica médica en emprendimento científico y cultural, habiéndose convertido la medicina, de hecho, en una profesión, según el sentido etimológico y sacerdotal del vocablo (del latín professio: profesar, confesar), y siendo promovida a la más filantrópica de las artes griegas: el médico no sólo será un virtuoso técnico, sino también un técnico virtuoso.

La excelencia, cultivada en Grecia Antigua con la denominación de areté, significaba originalmente una determinada condición física que permitía a alguien hacer bien una cosa. "Excelencia", antes de significar virtud o valor moral como la conocemos hoy, representaba perfeccionamiento físico. El vocablo "aretê" significa bueno, mejor en relación con los otros, excelente. Esas expresiones, traducidas por los romanos como virtudes (virtus: virtud, virtuosismo) se volvieron definidoras del carácter profesional e imperativo ético para obtener la excelencia técnica.

Excelencia y moral no pueden existir por separado. Para que un individuo ejerza determinado oficio es necesario que él sea antes un buen (excelente) profesional y, después, un profesional bueno (excelente)(3).

\section{La calidad en salud}

Hoy en día, excelencia representa una calidad técnica resultante del entrenamiento y de la formación intelectual, por regla general adquiridos durante el proceso educativo formal o, tratándose de las artes, oriundas del desarrollo sincronizado y continuado de prácticas que transforman a su autor en un individuo virtuoso (excelente).

Una técnica se manifiesta por la capacidad de desarrollar ciertas habilidades cognitivas y emplearlas realizando algo útil para la sociedad. No basta saber una técnica ni perfeccionarla, es necesario que su finalidad atienda a una demanda social. El puro saber y el puro hacer no constituyen conocimiento ni son suficientes por sí mismos; es necesario que conlleven el contexto de la sociedad, que sean útiles y que promuevan satisfacción para quienes sirven.

La excelencia, la búsqueda del mérito técnico, debe estar configurada como una acción apropiada, identificada con lo que es propio del arte (lege artis). Excelente es aquello que jueces idóneos declaran bien hecho y que los pares ilustres reconocen como adecuado. El saber hacer informado, que como tekhné se consuma 
en la palabra justa, en el gesto necesario, en el método felizmente adaptado al objetivo(4).

La medicina atravesó los tiempos impregnada por avances crecientes, propiciados por los progresos del conocimiento técnico-científico, momento en que también recibió influencias variadas de cuño filosófico, religioso, económico y social.

En la antigüedad la ética hipocrática se basaba en el principio de la beneficiencia vertical o impositiva (el paternalismo médico), dentro de la concepción de que la gestión del cuerpo del paciente no podría ser realizada sino por una persona cualificada para ello: el médico.

En el siglo XVII surge el concepto de la libertad de conciencia que, en el siglo siguiente, se vuelve más consistente y se materializa en la elaboración de los derechos humanos básicos, los llamados derechos individuales o subjetivos, como el derecho a la vida, a la salud, a la libertad y a la propiedad.

La afirmación de esos derechos presupone el reconocimiento de la autonomía de los individuos para gobernar sus vidas y sus intereses o asuntos, como la religión y, después, la política.

Esas conquistas liberales, victoriosas en los siglos XVII y XVIII, caracterizadas por la admisión del pluralismo y del autogobierno, y de las discrepancias de creencias religiosas y opiniones políticas, vinieron a consolidar los derechos de la primera generación(5). Sin embargo, no fueron suficientes para alcanzar el espacio de gobernabilidad del cuerpo.

Es sorprendente observar que la revolución liberal no haya conseguido llegar a la medicina, cuyas decisiones importantes continuaban siendo adoptadas por los médicos de acuerdo con su sistema de valores, sin contar con los valores de los pacientes. De esa forma, el paternalismo médico consiguió llegar incólume hasta la mitad del siglo XX, con una relación clínica basada en el modelo clásico, considerado monárquico o vertical, en el cual las relaciones entre médico y paciente son-característicamente- relaciones de mando y obediencia.

En el inicio del siglo XX arranca el cambio de ese modelo, de monárquico hacia oligárquico, a través de la coparticipación del poder médico con otros profesionales, pero sin renunciar a la relación vertical con el paciente. Solamente en las últimas décadas del siglo XX ocurre la nivelación de la relación clínica. El resultado de ese proceso fue la inclusión del paciente en el proceso de toma de decisiones, obteniéndose de esa forma la democratización de las relaciones sanitarias con la participación activa de sus usuarios.

Surge en la práctica médica el primer código de derecho de los enfermos: derecho a cuidados médicos de buena calidad, a la libertad de elección, a la autodeterminación, a la información, al rechazo de un tratamiento, a la confidencialidad, a la educación en salud, a la libertad religiosa y a la dignidad.

Se desarrolla una nueva moral de perfil normativo (basada en la diferenciación entre hechos y valores, teniendo la calidad de vida como su "regla de oro"), de cuńo autonomista (basada en el respeto a la autodeterminación de la persona en lo que se refiere a su salud, vida y muerte) y de comportamiento social o civil (postura crítica y democrática)(6).

El "profesionalismo médico" consagró los principios de primacía del bienestar del paciente, de su autonomía y de justicia social(7). El bienestar del paciente es el primero de todos los principios y se basa en la dedicación del médico en favor del interés de aquel. Ese altruismo característico de la profesión contribuye al desarrollo de la confiabilidad, elemento central para la armonía de la relación médico-paciente. Aun existiendo presiones mercantiles y sociales, además de exigencias administrativas contrarias, ellas no deben comprometer ese principio.

El principio de autonomía se refiere al respeto del médico para con la libertad de elección del paciente. Los médicos deben ser honestos y sinceros con sus pacientes, permitiéndoles tomar decisiones sobre los procedimientos diagnósticos y terapéuticos, después de previas aclaraciones.

Las decisiones de los pacientes sobre los cuidados médicos deben predominar sobre cualquier otra decisión en la medida en que sean coherentes con la buena técnica y no conduzcan a situaciones inapropiadas, tanto desde el punto de vista moral como legal.

Por último, el principio de la justicia social impele a los médicos a que contribuyan activamente a la eliminación de innumerables prácticas de discriminación del ser humano en los sistemas de salud, sobre todo por lo que respecta a las cuestiones de raza, género, situación socioeconómica, categoría étnica, religión o cualquier otra categoría social. 


\section{La calidad profesional}

La profesión médica tiene como carácter ético la práctica de la virtud de la excelencia. Esta exige del profesional tanto excelencia física o técnica como moral. La competencia profesional no se refiere sólo a la habilitación académica, sino también al ejercicio calificado de acuerdo con el patrón de excelencia determinado por el conocimiento y entrenamiento en su área de actuación.

Durante mucho tiempo la medicina estuvo avalada por un conocimiento empírico, muchas veces misterioso y trascendental, como bien demuestra su historia desde la Antigua Grecia hasta el siglo XIX, cuando se inició su desarrollo científico. Hasta entonces se practicaba una medicina basada en manifestaciones sintomáticas y objetivas, volcada en los cuidados del enfermo, apuntando a disminuir sus sufrimientos. Hoy, la extraordinaria competencia adquirida a través del conocimiento médico puede poner al profesional frente a innumerables dilemas éticos, contrarios al clásico menester de la medicina de la mejoría de las condiciones de salud; los avances científicos pueden inducir al médico a transformarse en mero manipulador de la vida humana.

La amplitud de los nuevos conocimientos de la genómica y la inmunología, sumados a la innovación en el área de la química fina, determinaron la aparición de antibióticos más potentes, el desarrollo de nuevas técnicas quirúrgicas (sobre todo en el campo de los transplantes), la reproducción asistida y la terapia genética. Es reciente el uso de nuevos materiales y medicamentos en las áreas de estética y sexología, además del desarrollo de increíbles máquinas de diagnóstico que escudriñan toda la intimidad biológica del cuerpo humano(8).

Esta gigantesca parafernalia puesta al servicio de la medicina contemporánea incentiva e induce a sus profesionales a utilizar la tecnología más reciente, bajo pretexto de sanar enfermedades y mantener vivo al paciente a cualquier costo, agotadas ya todas las posibilidades biológicas para la conservación de una calidad de vida digna, además de contribuir al encarecimiento de la asistencia médica y de salud.

Las tecnologías modernas sólo se justifican si están condicionadas a una efectiva mejoría de la calidad de vida y de salud del ser humano. De otro modo, representan una forma de dominación y usurpación de la cultura médica por la máquina o, aún más, la sumisión del paciente a la ideología del cientificismo o a la lógica de mercado, que contribuye a la obtención de lucros injustificables por la industria de la salud y descuida la evaluación prudente de la relación entre el costo, los riesgos y los posibles beneficios para el paciente.

Actualmente existe un continuo desfilar de novedades tecnológicas derivadas de los avances de las ciencias médicas y biológicas surgidas desde la mitad del siglo XX, materializadas bajo la forma de nuevos equipamientos, procedimientos clínicos y medidas profilácticas. Todo ello conforma un acervo de innovaciones que confiere a la salud el privilegio de constituirse en uno de los sectores de la economía mundial que más ha crecido en los últimos tiempos.

Esta realidad promueve al mismo tiempo dos constataciones. La primera de carácter optimista, en razón de los numerosos beneficios que las innovaciones tecnológicas vienen propiciando con relación a la salud y el bienestar de las personas; sin embargo, y esta es la segunda, está provocando polémicas sobre los costes y beneficios obtenidos por la sociedad en general, teniendo en cuenta la creciente carga financiera asumida por los sistemas nacionales de salud para incorporar dichas innovaciones, además de los procedimientos éticamente cuestionables que tales innovaciones están suscitando.

En suma, el sector salud tiene características peculiares que, por un lado, lo vinculan íntimamente con el desarrollo científico y tecnológico, generando impactos en la economía y en la sociedad; por otro, promueve consecuencias directas sobre la salud individual y la calidad de vida de las poblaciones.

Las íntimas relaciones de la praxis médica, sea clínica u hospitalaria, con las innovaciones tecnológicas están ocasionando el aumento de dilemas éticos, habiéndose transformado la medicina, en este umbral del siglo XXI, en un instrumento de la nueva utopía de la humanidad: la utopía de la salud y del cuerpo perfectos(9), de todo lo cual resulta que los avances tecnológicos pueden estar induciendo una cultura de transformar al profesional médico más en un manipulador de vidas que en promotor de la salud humana. 


\section{Ética de la calidad en salud}

Los dos principios que deben dirigir la calidad de la atención en salud, en correspondencia con la excelencia propiciada por el conocimiento y la tecnología de las ciencias médicas, son la equidad y la integridad.

El principio de la equidad puede presentarse mediante diferentes concepciones. Una de ellas, en el sentido genérico, se funde con la propia noción de justicia, que tiene por finalidad el establecimiento de reglas justas para la sociedad (como en el vocablo latino "aequale", usado como sinónimo de iguales). El otro significado de equidad dice relación con el respeto a la adecuación de las normas genéricas para cada contexto específico: "Equidad es la adaptación de una norma al caso singular, que no permite una perfecta equiparación a los casos previstos", significando que la "desigualdad de tratamiento corresponde a un reconocimiento de la desigualdad de situación"(10).
Equidad puede significar la opción de tratar desigualmente los desiguales, ya que el acceso a bienes y servicios en países de bajo desarrollo social, como los existentes en América Latina, podrá tener un carácter punitivo para las poblaciones pobres en las periferias de los grandes centros urbanos o en el medio rural.

El principio de integridad es la garantía de cuidados integrales y necesarios para una vida saludable, que presupone prevención, promoción y tratamientos. Es uno de los principios más importantes para demostrar que la atención a la salud debe considerar las necesidades específicas de personas o grupos de personas.

Para que haya integridad se debe considerar cada persona según su necesidad, incluyendo niveles diferenciados de complejidad. De modo que segmentos específicos -como jóvenes, mujeres, ancianos, portadores de VIH y otras enfermedades, gestantes, drogadictos y portadores de enfermedades mentales- deben ser blancos de una atención especial o diferenciada(11).

\section{Referencias}

1. Mainetti JA. Bioética médica: introducción histórica. La Plata: Quirón; 1989.

2. Edelstein L. The Professional Ethics Of The Greek Physician. In: Reiser SJ, et al. Ethics In Medicine (Historical Perspectives And Contemporary Concerns). London: The Mit Press; 1961.

3. Gracia D. Calidad y excelencia en cuidado de la salud. En: Lolas F. (editor) Bioética y cuidado de la salud. Equidad, calidad, derechos. Santiago de Chile: Programa Regional de Bioética OPS/OMS; 2000: 35-52.

4. Lolas F, Drumond JG de F. Fundamentos de uma antropologia bioética: O apropriado, o bom e o justo. Sáo Paulo: Loyola; 2007.

5. Bobbio N. A era dos direitos. Rio De Janeiro: Campus; 1992.

6. Drumond JG de F. O "ethos" médico: A velha e a nova moral médica. Montes Claros: Editora Unimontes; 2005.

7. Sox HC. Medical professionalism in the new millenium: A physician charter. Ann Intern Med 2002; 136: 243-246.

8. Drumond JG de F. Ethical aspects of innovation in health. In: Global Forum Update on Research for Health 2008, Volume 5. Pro-Book Publishing Limited; 82-85.

9. Sfez L. A saúde perfeita: crítica de uma nova utopia. São Paulo: Loyola; 1996.

10. Bobbio N. Teoria geral da politica: a filosofia politica e as liçôes dos clássicos. Trad. Daniela B. Versiani. Rio De Janeiro: Campus; 2000.

11. Drumond JG de F. Proyecciones de regulaciones sanitarias en Brasil. En: Lolas F. (editor). Dimensiones éticas de las regulaciones en salud. Santiago de Chile: Programa de Bioética OPS/OMS, Centro Interdisciplinario de Estudios en Bioética, Universidad de Chile; 2009.

Recibido: 23 de junio de 2010

Aceptado: 18 de julio de 2010 